\title{
PROPAGASI INDOOR GELOMBANG RADIO PERANGKAT XBEE DI RUMAH SAKIT IBU DAN ANAK BUDHI MULIA PEKANBARU
}

\author{
Fadhli Palaha* dan Zaini ** \\ *Mahasiswa S2 Teknik Elektro Univertsitas Andalas \\ **Staff Pengajar Teknik Elektro Universitas Andalas
}

\begin{abstract}
Abstrak-Penelitian ini bertujuan untuk mengetahui pembacaan propagasi frekuensi radio (sinyal RSSI) dalam gedung yang berorientasikan objek dengan menggunakan perangkat XBee. Terdapat beberapa faktor yang mempengaruhi kinerja perangkat ini ketika mengukur sinyal RSSI.Untuk melakukan pembacaan propagasi frekuensi radio ini digunakan metode jaringan nirkabel Zigbee IEEE 802.15.4. Jaringan ini menggunakan biaya teknologi yang efektif jauh lebih ringan. Propagasi frekuensi radio XBee ini diaplikasikan dengan sebuah alat yang dirancang dan berfungsi sebagai Tx (pengirim) dan $R x$ (penerima) yang masing-masing $\mathrm{Tx}$ dan $\mathrm{Rx}$ ini mempunyai bagian komponen sendiri. Dari hasil pengujian pembacaan sinyal RSSI ini dapat disimpulkan bahwa jika banyak yang menghalangi, maka kekuatan sinyalnya sangat kecil. Sebaliknya jika yang menghalanginya sedikit, maka kekuatan sinyalnya sangat besar. Hasil pembacaan data Xbee yang berbentuk - dbm ini bisa dilihat melalui perangkat lunak ZiggBee Operator.
\end{abstract}

Kata Kunci: Sinyal Radio Frequency RSSI, Konstruksi bangunan bagian dalam, XBee, Zigbee

\begin{abstract}
The aim of this study is to know the propagacy reading of radio frequency in a building oriented to objects by using Xbee peripheral. There are some factors influenced the accuracy of this peripheral while measuring the RSSI signal. To do this propogacy reading of radio frequency used Zigbee IEEE 802.15.4 wireless network. This network has the cheaper cost in technology. This propogacy is applied with a tool designed and functioned as Tx (sender) and the Rx (receiver) whereas each of the Tx and $\mathrm{Rx}$ has its own component parts. The results of the reading of this RSSI signal is if there are so many barriers that blocks, the signal strength is very small. And if there is a little barrier that blocks, the signal strength is very big. The reading of data XBee-shaped in $\mathrm{dbm}$ can be seen through a software called ZiggBee Operator.
\end{abstract}

Keywords: Signal of Radio Frequency RSSI, indoor construction, XBee, Zigbee

\section{PENDAHULUAN}

Jaringan Zigbee IEEE 802.15.4 memungkinkan untuk melakukan objek lokalisasi dengan menggunakan biaya yang efektif untuk teknologi nirkabel, beberapa implementasi telah dilakukan untuk objeklokasi yang juga termasuk kedatangan perbedaanwaktu .[1]

Dari metode yang ada dan memanfaatkan keberadaan IEEE 802.11 dasar stasiun dengan kekuatan daya pancar radio sekitar $100 \mathrm{~mW}$ per base station. Radio tersebut di kelas yang berbeda dari kekuatanIEEE802.15.4 radio daya rendah yang biasanya mengirimkan pada tingkat daya yang rendah mulai dari $52 \mathrm{~mW}$ ke $29 \mathrm{~mW}$. Ketersediaan daya yang luas dan lebih besar jumlah radio IEEE 802.15.4 telah menghidupkan kembali minat untuk objek lokasi berbasis kekuatan sinyal dalam jaringan sensor. Meskipun meningkat pesat popularitas IEEE 802.15.4 radio dan kekuatan sinyal objek, ada kekurangan tentang karakterisasi fundamental faktor yang berkontribusi terhadap variasi kekuatan sinyal yang besar[2].Maka penelitian ini membahas tentangPropagasi Indoor Gelombang Radio XBee Di Rumah Sakit Ibu Dan Anak Bdhi Mulia Pekanbaru yang bertujuan untuk pembacaan frekuensi radio di dalam gedung yang berorientasikan objek seperti dinding, logam atau benda-benda lain yang di antaranya banyak faktor untuk mempengaruhi keakurasian kinerja XBee ketika mengukur RSSI dan mengurangi konsumsi daya keseluruhan jaringan yang untuk daya pancar dalam kondisitertentu.[3]

Dalam tulisan ini kita membandingkan dua teknologi yang munculuntukwirelessjaringan sensorStandar IEEE 802.15.1 dan 802.15.4. Dari fitur utamaProtokol MAC didefinisikan 
oleh standar-standar tersebut, menggambarkan system operasi, dan membandingkannya dari segi karakteristik kinerja suchas ( akses dan end-to-end paket penundaan ), pemanfaatan bandwidth, dan skalabilitas untuk penyebaran jaringan yang besar.[4]

\section{TINJAUAN PUSTAKA}

\subsection{Dasar Perambatan Frekuensi Radio}

Frekuensi radio (RF) yaitu Sinyal dengan frekuensi tinggi yang memiliki arus bergantian (alternating curent) AC melewati konduktor dan diradiasikan melalui antena ke udara yang disebut sebagai frekuensi radio, ketika signal tersebut memancar ke udara akan berubah menjadi gelombang radio yang bergerak menjauhi sumber (antenna) kesetiap arah pada sebuah garis lurus dengan waktu bersamaan. Gambar dibawah ini menunjukkan medan elektromagnetik dimanan medan megnet ini tegak lurus terhadap medan listrik

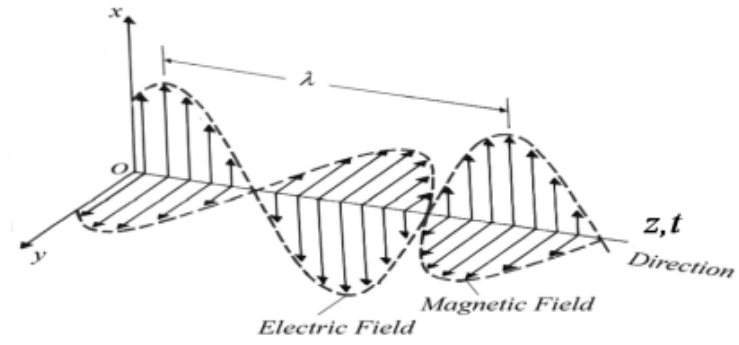

Gambar 2.1 Medan Elektromagnetik

Perambatan gelombang radio dinyatakan dengan persamaan rumus yaitu :

$$
P_{r}(d)=\frac{P_{t} G_{t} G_{r} \lambda^{2}}{(4 \pi)^{2} d^{2} L}
$$

Untuk dapat memaksimalkan jangkauan dari sebuah alat yang mentransmisikan gelombang radio haruslah dapat memahami sifat-sifat dasar dari frekuensi radio itu sendiri saat di transmisikan yaitu antara lain :

\section{Penerimaan/Gain}

Sebuah gain dapat terbentuk dari proses aktif seperti penambahan RF amplifier atau sebuah antena yang dirancang untuk memiliki kemampuan penerimaan yang tinggi karena dapat memfokuskan beamwidth sinyal, selain proses aktif ada pula proses yang pasif seperti signal RF yang terefleksi dan bergabung dengan signal utama sehingga memperkuat signal utama.

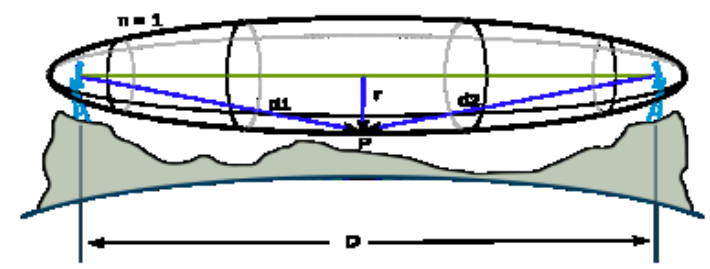

Gambar 2.2 Sifat Gain(Ummi Nurulhaiza Za'bahand O.Sidek)

Dengan penerimaan gelombang radio dinyatakan pada persamaan rumus : $G=\frac{4 \pi A_{e}}{\lambda^{2}}$

2. Kehilangan/Loss

Loss adalah suatu penurunan kekuatan sinyal yang disebabkan pada kabel yang menyambungkan dari alat RF ke antenna beserta konektornya dan objek yang terdapat pada jalur transmisi radio tersebut dan harus mampu memperhitungkan loss pada rangkaian peralatan RF karena radio memiliki sensitifitas atau yang biasa disebut receive sensitivity threshold dimana radio dapat membedakan signal dan noise dengan jelas.

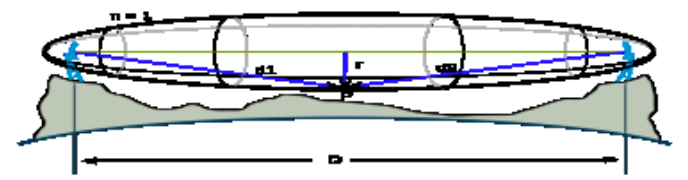

Gambar 2.3 Sifat Loss (Ummi Nurulhaiza Za'bahand O.Sidek)

\section{Pantulan/Reflection}

Pantulan propagasi gelombang terkena objek yang besar dibandingkan dengan panjang gelombang dari gelombang yang terpropagasi. Pantulan dapat terjadi dengan dinding, gedung, bahkan bumi dan banyak hambatan lainnya.

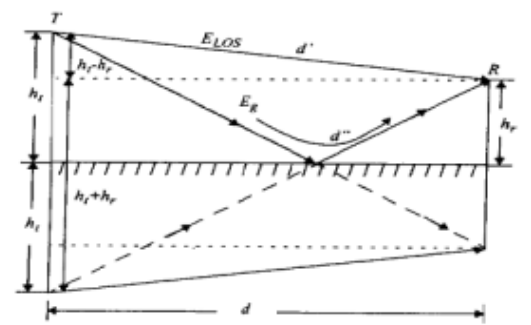

Gambar 2.4 Ilustrasi Sifat Reflection

Persamaan daya yang diterima :

$$
P_{r}=P_{t} G_{r} G_{t} \frac{h_{t}^{r} h_{r}^{t}}{d^{4}}
$$

Dengan rugi-rugi permodelan diatas digunakan persamaan :

$$
P L(d B)=40 \log d-\left(10 \log G_{t}+10 \log G_{r}+20 \log h_{t}+20 \log h_{r}\right)
$$

\section{Pembiasan/Refraction}


Pembiasan adalah pembelokan gelombang radio ketika melewati medium yang berbeda kepadatannya. Pembiasan terjadi karena ketika gelombang melewati medium yang lebih padat maka gelombang akan berbelok sehingga arahnya berubah namun sebagian lagi akan berbelok memasuki medium dengan arah yang sudah tidak sama lagi. Permasalahan ditemukan pada gelombang pancaran RF dengan peruntukan jarak yang jauh karena rentan terhadap perubahan atmosfir yang dapat merubah arah dari gelombang RF itu sendiri.

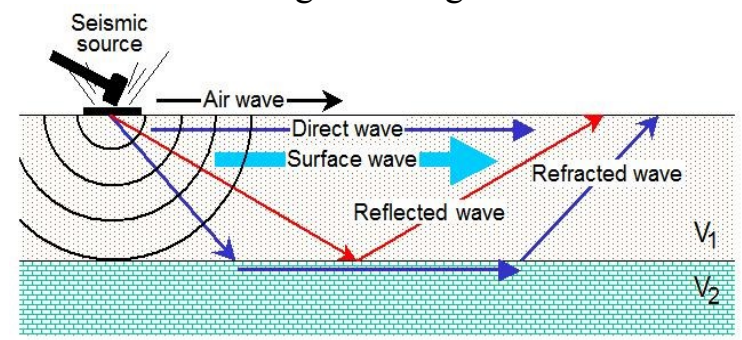

Gambar 2.5 Ilustrasi Sifat Refraction

\section{Pembelokkan/Difraction}

Pembelokkan terjadi ketikan jalur transmisi antar pemancar dan penerima terhalang oleh permukaan yang tidak rata atau kasar. Di frekuensi yang tinggi difraksi menghasilkan amplitudo dan polarisasi yang dihasilkan oleh difraksi itu sendiri.

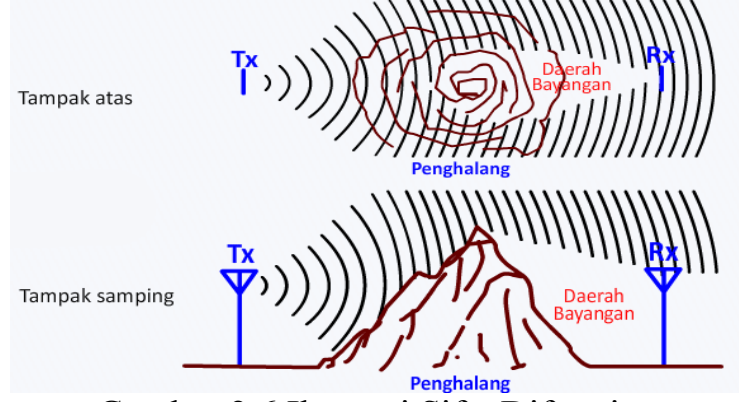

Gambar 2.6 Ilustrasi Sifat Difraction

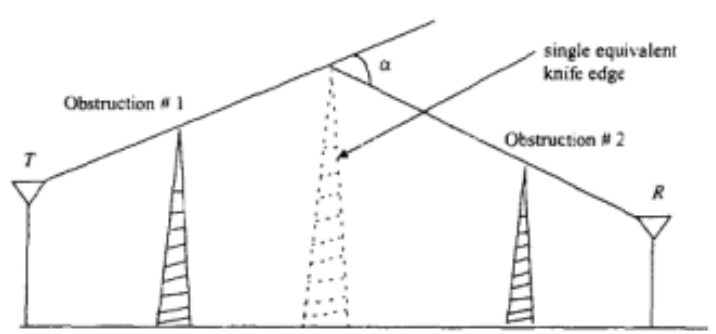

Gambar 2.7 Knife-Edge Diffraction

Pada diffraction ini mempunyai rugi-rugi pembelokkan yang dinyatakan dalam persamaan berikut :

$$
v=h \sqrt{\frac{2\left(d_{1}+d_{2}\right)}{\lambda d_{1} d_{2}}}:
$$

\section{Penyebaran/Scattering}

Penyebaran/scattering adalah gelombang melewati medium yang terdiri dari objek yang memiliki ukuran lebih kecil dan dari panjang gelombang yang jumlah hambatan yang besar. Gelombang menyebar dihasilkan oleh permukaan yang kasar, benda kecil dan tidak rata. Inilah yang dapat merusak sinyal dari RF itu sendiri dikarenakan pantulan yang ditimbulkan menyebar kesegala arah dan menghasilkan amplitudo kecil yang dapat saling mematikan sinyal utama.

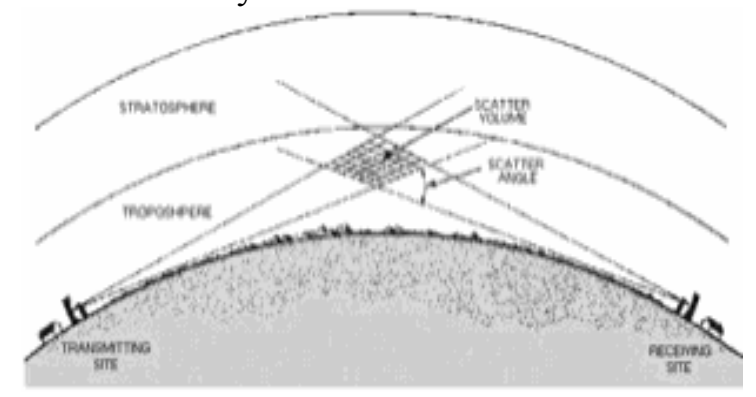

Gambar 2.8 Ilustrasi Sifat Scattering

Dalam scattering gelombang ini mempunyai rugi-rugi yang dinyatakan dengan persamaan berikut :

$$
h_{\mathrm{c}}=\frac{\lambda}{8 \sin \theta_{i}}
$$

\section{Penyerapan/Absorption}

Absorption terjadi ketika signal mengenai suatu objek dan terserap kedalam material tersebut namun signal tidak dapat melewati,menembus, ter-pantul, atau berbelok mengelilingi objek tersebut.

\subsection{Perambatan Frekuensi Radio Didalam Ruangan}

Pada penjelasan sub bab diatas sudah diketahui sifat-sifat frekuensi radio baik diluar maupun didalam adalah sama namun perbedaan yang mendasar di dalam ruangan yaitu jarak yang ditempuh jauh lebih kecil, rentang Tx-Rx yang lebih kecil dan di jumpai bermacam variasi lingkungan anatara lain: material bangunan, tipe bangunan, layout bangunan, sekat ruangan dll.

Dalam penelitian Perambatan frekuensi radio di dalam ruangan ini dibagi menjadi dua kategori yaitu :

a. perambatan frekuensi radio terpisah sekat.

Sekat di area gedung sangat berperan penting karena dapat melemahkan sinyal radio ketika melewati sekat-sekat tersebut. 
Sekat-sekat dalam ruang dibedakan menjadi dua yaitu:

1. Hard partition yaitu struktur bangunan yang permanen seperti dinding, plafon, dan lantai beton.

2. Soft partition yaitu struktur bangunan yang tidak permanen atau hanya bersifat sementara seperti lemari, meja yang bisa di pindah-pindahkan

b. perambatan frekuensi radio antar lantai gedung.

Pada penelitian ini diasumsikan bahwa penerima dan pengirim berada dalam satu gedung tetapi terpisah lantai mengakibatkan sinyal radio melemah antar lantai yang mempengaruhi beberapa factor seperti dimensi gedung,material bangunan, dan keadan sikatar bangunan.

\subsection{XBee}

XBee merupakan modul yang memungkinkan Arduino untuk berkomunikasi secara wireless menggunakan protokol ZigBee. ZigBee beroperasi pada spesifikasi IEEE 802.15.4 radio fisik dan beroperasi pada band berlisensi termasuk $2.4 \mathrm{GHz}, 900 \mathrm{MHz}$ dan 868 MHz. Modul ini memungkinkan komunikasi wireless dalam jangkauan hingga 30 meter (dalam ruangan) atau 100 meter (luar ruangan)

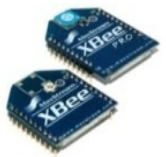

Gambar 2.9 Modul XBee.

Pada dasarnya, XBee merupakan komunikasi serial. Akan tetapi, apabila mode API digunakan, dibutuhkan pemaketan data RF.

\subsubsection{AT Command}

Pada mode API yaitu perintah untuk berkomunikasi langsung dengan perangkat Hardware seperti misalnya beberapa parameter yang akan diatur atau hanya dibaca salah satunya proses pengecekan nomor serial XBee dengan format ATDH \& ATDL. Informasi berikutnya akan dijawab oleh XBee dengan mengirimkan bingkai API juga namun dengan identitas API yang berbeda yaitu AT Command Responses yang merupakan jawaban berupa nilai register yang sebelumnya ditanyakan melalui perintah AT

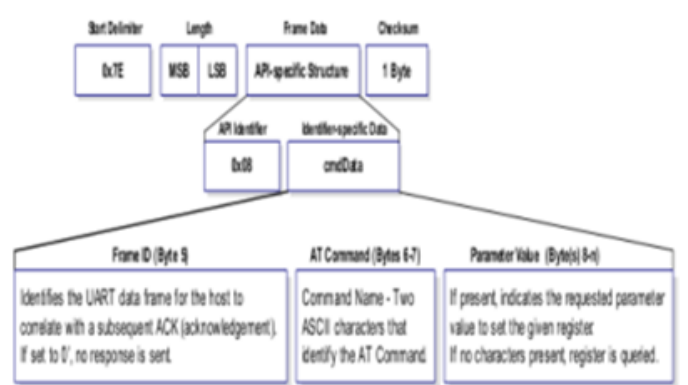

Gambar 2.10 Diagram Struktur Data Bingkai AT Command

\subsubsection{Command Response}

Command response merupakan jawaban dari sebuah permintaan nilai register yang dikirimkan pada identitas APIseperti pemaparan sebelumnya. Bingkai data pada mode identitas ini hampir sama dengan $A T$ Command namun pada nilai byte terakhir sebelum Checksum diisikan nilai register yang diminta pada permintaan sebelumny. Nilai register ini merupakan nilai $\mathrm{Hex}$ atau Non ASCII dari sebuah perintah dan disertai keadaan atau status paket data yang dikirimkan sebelumnya apakah sesuai dengan nama perintah atau nilai yang dikirimkan sebagai patameter valid atau tidak.

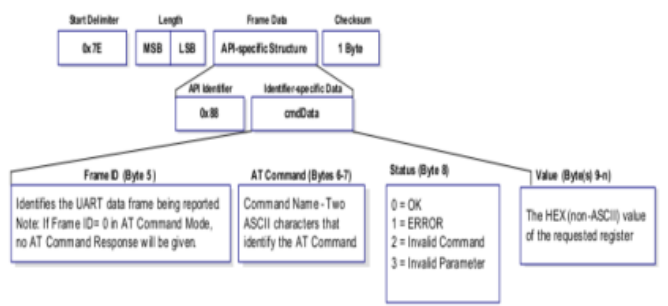

Gambar 2.11 Diagram Struktur Data Bingkai AT Command Response

Sebagai contoh, pada AT Command mengirimkan ATD0 yang menanyakan keadaan pengaturan perangkat $\mathrm{I} / \mathrm{O}$ pada pin Analog/Digital 0, maka AT Command Response akan menjawab dengan deretan bingkai data yang sama seperti yang dikirimkan, namun dilengkapi dengan status OK jika valid perintah yang dikirimkan dan nilai dari keadaan pin Analog/Digital 0 tersebut misalkan 4 yang berarti keluaran digital Low.

\section{PERANCANGAN} DAN 
Pada penelitian ini mengukur setiap pembacaan RSSI di tiap ruangan, bentuk dari gedung yang akan diteliti seperti gambar dibawah ini:

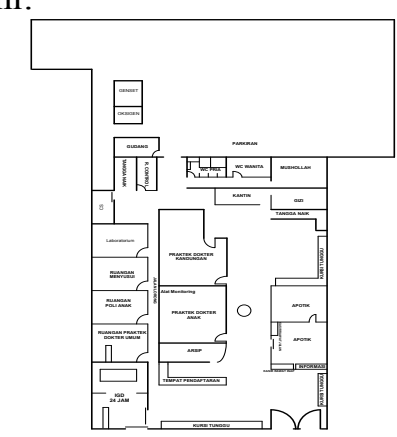

Gambar 3.1 Denah Lantail

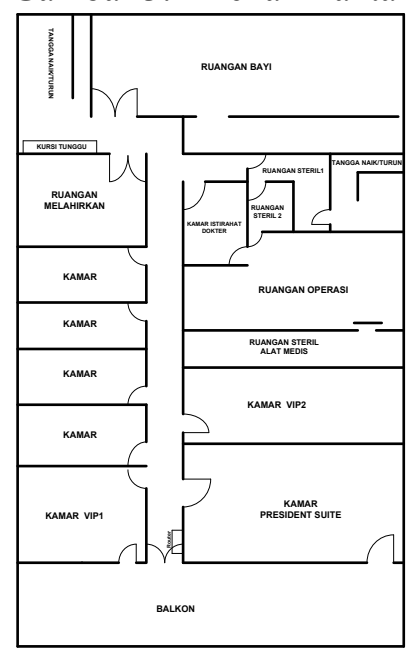

Gambar 3.2 Denah Lantai II

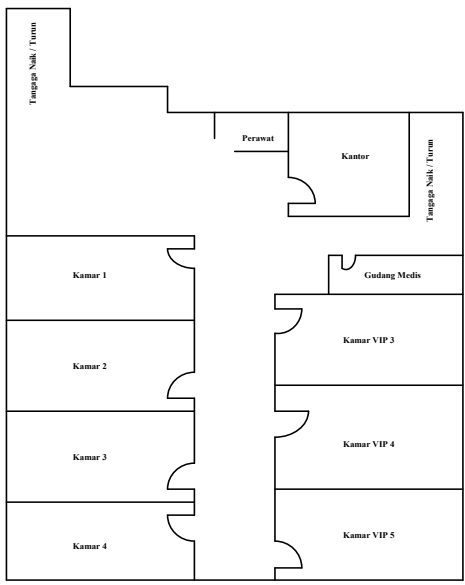

Gambar 3.3 Denah Lantai III

\subsection{Perancangan Sistem Alat}

Perancangan sistem alat ini dibuat untuk memberikan suatu gambaran atau informasi tentang pembacaan paket sinyal RSSI di gedung rumah sakit ibu dan anak pekanbaru yang bertujuan untuk berapa besar kekuatan sinyal RSSI di xbee series 2 dengan dibantu beberapa komponen lainnya yaitu arduino uno, DHT11, pulsesensor dan xbee adapter.

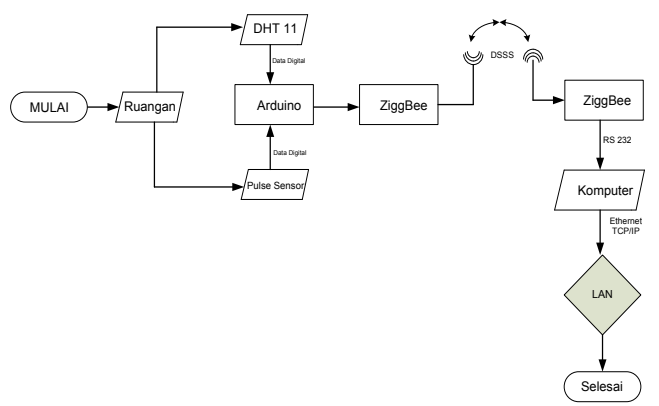

Gambar 3.4 Flow Chart Perancangan Alat Monitoring

\subsection{Rancangan Konfigurasi Sistem}

Langkah awal dalam pembuatan sistem ini ialah konfigurasi dari beberapa hardware.

- Rancangan Konfigurasi Rangkaian

Hardware yang akan dipakai ada ada dua jenis yaitu sebagai transmiter dan receiver. Masing-masing hardware di instalasi dengan bentuk yang berbeda. Gambar 3.3 dibawah ini merupakan rangkaian dari instalasi hardware sebagai transmiter.

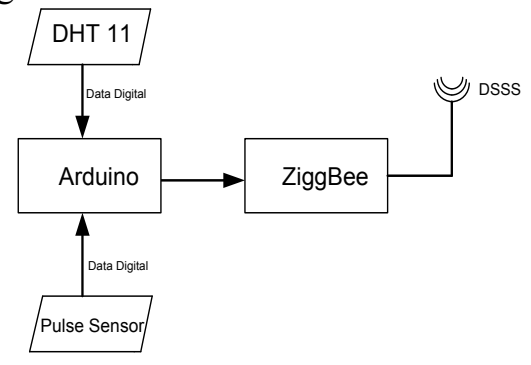

Gambar 3.5 Rancangan Instalasi pada transmiter wireless sensor

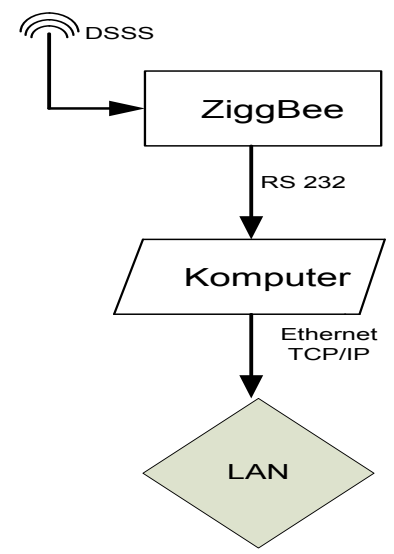

Gambar 3.6 Rancangan Instalasi pada receiverwireless sensor 


\section{HASIL DAN PEMBAHASAN}

Pembahasan penelitian ini adalah bagaimana pembacaan sinyal RSSI ini dengan menggunakan aplikasi zigbee operator dan penguraian dari suatu sistem yang utuh ke dalam bagian-bagian komponennya dengan maksud untuk mengidentifikasi dan mengevaluasi permasalahan.

\subsection{Pembacaan Sinyal RSSI yang diterima oleh Coordinator pada Lantai I}

Pengujian ini dilakukan dengan posisi end device/router diruang anak dan posisi coordinator/reciever selalu berpindah-pindah ruangan 1 ke ruangan lainnya yang tujuannya untuk pembacaan pengiriman paket RSSI yang diterima oleh coordinator dan hasilnya dapat dilihat pada tabel dan grafik berikut

Tabel 4.1 Data Hasil Pengujian RSSI Lantai I

\begin{tabular}{|c|c|c|}
\hline \multirow{2}{*}{ Ruangan } & \multicolumn{2}{|c|}{$\begin{array}{c}\text { Paket Data RSSI } \\
\text { (dbm) }\end{array}$} \\
\cline { 2 - 3 } & Hex & Dec \\
\hline dr. Anak & 63 & 99 \\
\hline dr. kandungan & 63 & 99 \\
\hline Apotik & 63 & 99 \\
\hline Reception & 63 & 99 \\
\hline UGD & 61 & 97 \\
\hline Poli Kebidanan & 61 & 97 \\
\hline Poli Anak & 62 & 98 \\
\hline Menyusui & 62 & 98 \\
\hline Laboratorium & 62 & 98 \\
\hline Control & 58 & 88 \\
\hline Cleaning Service & 56 & 86 \\
\hline Mushollah & 49 & 73 \\
\hline Gizi & 51 & 81 \\
\hline Gudang & 47 & 71 \\
\hline
\end{tabular}

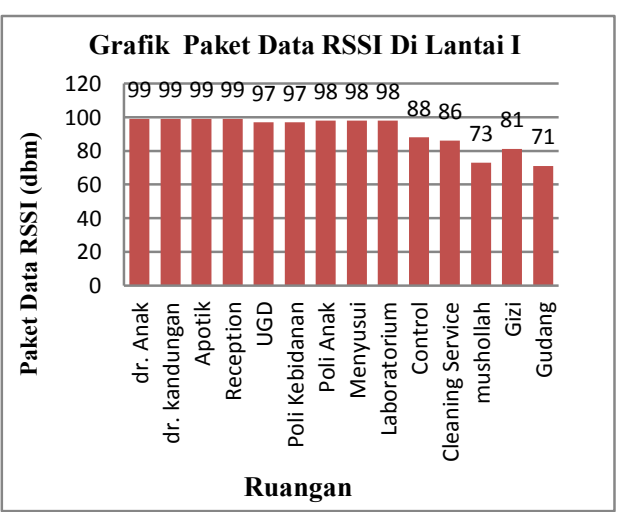

Gambar 4.1 Grafik Hasil Pengujian Paket RSSI Lantai I
Dari hasil pengujian didapatkanlah grafik yang menunjukkan nilai besaran kekuatan sinyal pada titik ruangan terhadap Coordinator yang diukur dalam satuan decibel $(\mathrm{dBm})$. Dalam grafik terlihat bahwa nilai kekuatan sinyal tertinggi yaitu $99 \mathrm{dBm}$ pada ruangan dr. anak, dr.kandungan, Apotik, reception di karenakan penghalang yang ada disekitarnya tidak begitu banyak yang menghalangi. Pada ruangan gudang, nilai terendah kekuatan sinyal berubah menjadi 71 $\mathrm{dBm}$, nilai ini mengalami perubahan yang sangat jauh dikarenakan penghalang yang menghalangi pembacaan sinyal ini sangat begitu banyak dan juga dipengaruhi oleh jauhnya pembacaan sinyal ini.

\subsection{Pembacaan Sinyal RSSI Yang diterima Coordinator Pada Lantai II}

Pengujian ini dilakukan dengan posisi end device/router diruang bayi di lantai II dan posisi coordinator / reciever selalu berpindah-pindah ruangan 1 ke ruangan lainnya yang tujuannya untuk pembacaan pengiriman paket RSSI diarea ini yang diterima oleh coordinator dan hasilnya dapat dilihat pada tabel dan grafik berikut.

Tabel 4.2 Data Hasil Pengujian Pembacaan Sinyal RSSI Lantai II

\begin{tabular}{|c|c|c|}
\hline \multirow{2}{*}{ Ruangan } & \multicolumn{2}{|c|}{$\begin{array}{c}\text { Paket Data RSSI } \\
\text { (dbm) }\end{array}$} \\
\cline { 2 - 3 } & Hex & Dec \\
\hline Bayi & $5 \mathrm{D}$ & 93 \\
\hline Melahirkan & $5 \mathrm{C}$ & 92 \\
\hline Steril 1 & $5 \mathrm{~B}$ & 91 \\
\hline Steril 2 & $5 \mathrm{~B}$ & 91 \\
\hline Operasi & $5 \mathrm{~A}$ & 90 \\
\hline Istirahat Dokter & 59 & 89 \\
\hline Steril Alat Medis & 57 & 87 \\
\hline Kamar Class 1 & 56 & 86 \\
\hline Kamar Class 2 & 55 & 85 \\
\hline Kamar Class 3 & 53 & 83 \\
\hline Kamar Class 4 & 52 & 82 \\
\hline Kamar VIP 1 & 50 & 80 \\
\hline Kamar VIP 2 & 53 & 83 \\
\hline Kamar PS & 50 & 80 \\
\hline
\end{tabular}




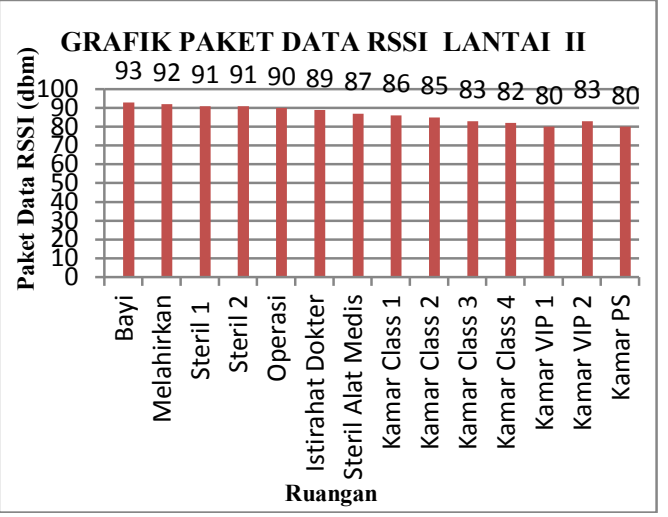

Gambar 4.2 Grafik Hasil Pengujian Pembacaan Sinyal RSSI Lantai II

Dari hasil pengujian didapatkanlah grafik yang menunjukkan nilai besaran kekuatan sinyal pada titik ruangan terhadap Coordinator yang diukur dalam satuan decibel $(\mathrm{dBm})$. Dalam grafik terlihat bahwa nilai kekuatan sinyal tertinggi yaitu $93 \mathrm{dBm}$ yaitu pada ruangan bayi di sebabakan oleh penghalang yang ada disekitarnya tidak begitu banyak yang menghalangi. Pada ruangan kamar VIP 1, nilai terendah kekuatan sinyal berubah menjadi $80 \mathrm{dBm}$, nilai ini mengalami perubahan yang sangat jauh dikarenakan penghalang yang menghalangi pembacaan sinyal ini sangat begitu banyak dan juga dipengaruhi oleh jauhnya pembacaan sinyal ini.

\subsection{Pembacaan Sinyal RSSI Yang Diterima Coordinator Pada Lantai III}

Pengujian ini dilakukan dengan posisi end device/router diruang kantor RSIA di lantai III dan posisi coordinator / reciever selalu berpindah-pindah ruangan 1 ke ruangan lainnya yang tujuannya untuk pembacaan pengiriman paket RSSI diarea ini yang diterima oleh coordinator dan hasilnya dapat dilihat pada tabel dan grafik berikut

Tabel 4.3 Data Hasil Pengujian Pembacaan Sinyal RSSI Lantai III

\begin{tabular}{|c|c|c|}
\hline \multirow{2}{*}{ Ruangan } & \multicolumn{2}{|c|}{$\begin{array}{c}\text { Paket Data RSSI } \\
\text { (dbm) }\end{array}$} \\
\cline { 2 - 3 } & Hex & Dec \\
\hline Kantor & 63 & 99 \\
\hline Kamar Class 1 & 63 & 99 \\
\hline Kamar Class 2 & 63 & 99 \\
\hline Kamar Class 3 & 63 & 99 \\
\hline
\end{tabular}

\begin{tabular}{|c|c|c|}
\hline Kamar Class 4 & 62 & 98 \\
\hline Kamar VIP 3 & 61 & 97 \\
\hline Kamar VIP 4 & 60 & 96 \\
\hline Kamar VIP 5 & $5 \mathrm{~F}$ & 95 \\
\hline Gudang Medis & 63 & 99 \\
\hline
\end{tabular}

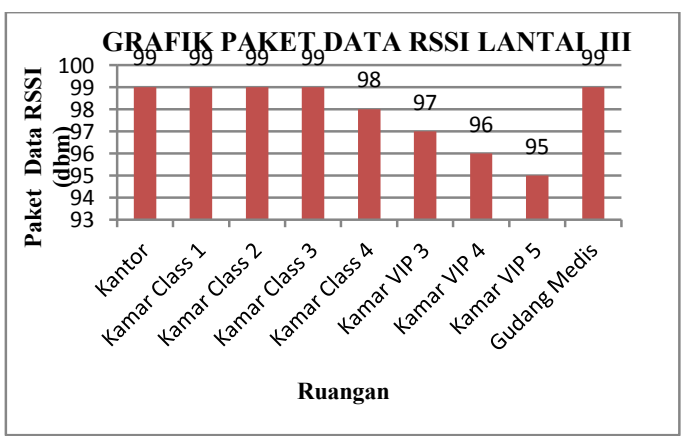

Gambar 4.3 Grafik Hasil Pengujian Pembacaan Sinyal RSSI Lantai III

Dari hasil pengujian didapatkanlah grafik yang menunjukkan nilai besaran kekuatan sinyal pada titik ruangan terhadap Coordinator yang diukur dalam satuan decibel $(\mathrm{dBm})$. Dalam grafik terlihat bahwa nilai kekuatan sinyal tertinggi yaitu $99 \mathrm{dBm}$ yaitu pada ruangan kantor, kamar class 1, kamar class 2, kamar class 3 dan gudang medis di sebabakan oleh penghalang yang ada disekitarnya tidak begitu banyak yang menghalangi. Pada ruangan kamar VIP 5, nilai terendah kekuatan sinyal berubah menjadi $95 \mathrm{dBm}$, nilai ini mengalami perubahan yang sangat jauh dikarenakan penghalang yang menghalangi pembacaan sinyal ini sangat begitu banyak dan juga dipengaruhi oleh jauhnya pembacaan sinyal ini

\subsection{Pengaruh Waktu Penerimaan}

Untuk mengukur kualitas waktu dari penerimaan data maka dilakukan dengan beberapa percobaan. Untuk percobaan pertama dengan menggunakan variasi delay yang diberikan pada arduino dengan jarak yang sama yaitu 15 meter.

Tabel 4.4 Tabel Pengiriman XBee berdasarkan Delay yang diberikan

\begin{tabular}{|c|c|}
\hline Delay (Sekon) & Waktu Penerimaan (Sekon) \\
\hline 2 & 1.98 \\
\hline 4 & 4.01 \\
\hline 6 & 5.00 \\
\hline 8 & 8.02 \\
\hline 10 & 9.95 \\
\hline 15 & 11.68 \\
\hline
\end{tabular}


Untuk percobaan kedua, dilakukan dengan menggunakan variasi jarak terhadap pengirim dan penerima.

Tabel 4.5 Waktu Pengiriman Berdasarkan Variasi Jarak

\begin{tabular}{|c|c|}
\hline Jarak $(\mathrm{m})$ & Waktu Penerimaan \\
\hline 5 & 1.98 \\
\hline 10 & 2.18 \\
\hline 15 & 3.13 \\
\hline 20 & 3.93 \\
\hline 25 & 4.65 \\
\hline
\end{tabular}

\subsection{Analisa Pengaruh Waktu Penerimaan}

Pada percobaan pertama, dilakukan dengan melakukan variasi delay dengan jarak yang sama. Jadi, pengaruh diberikan delay berbeda tidak mempengaruhi dari kualitas pengiriman dan penerimaan data.

Pada percobaan kedua, dilakukan dengan melakukan variasi jarak dengan delay pada pengiriman sama. Didapatkan hasil semakin jauh jarak antara transmitter dan receiver maka semakin lama waktu pengiriman. Hal ini dipengaruhi oleh adanya redaman, pantulan dan loss yang ada pada udara. Sehingga, data yang dikirimkan memiliki delay waktu atau tidak terkirim sama sekali. Berikut grafik dari variasi jarak terhadap waktu penerimaan.

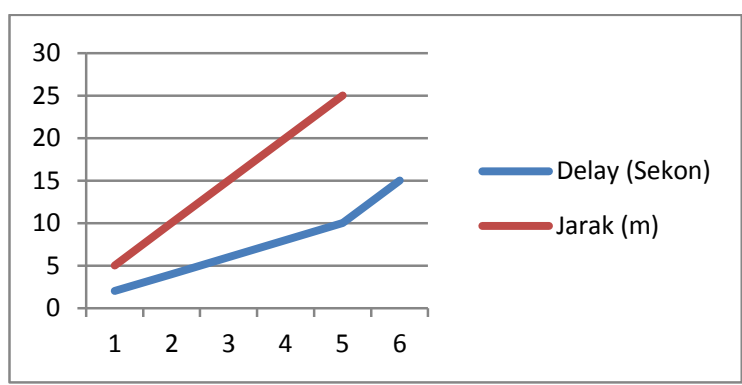

Gambar 4.4 Grafik Jarak vs Waktu Penerimaan Data

Pada gambar dapat diambil kesimpulan, bahwa semakin jauh jarak antara transmitter dan receiver, maka semakin lama waktu yang dibutuhkan dibutuhkan oleh receiver menerima data.

\subsection{Analisa pembacaan frame API di ziggbee operator}

Untuk hasil pembacaan API dengan ZiggBee Operator dapat dilihat pada gambar dibawah ini, untuk pembacaan berbentuk HEX dan data disimpan dalam bentuk file log oleh perangkat lunak ZiggBee Operator ini.

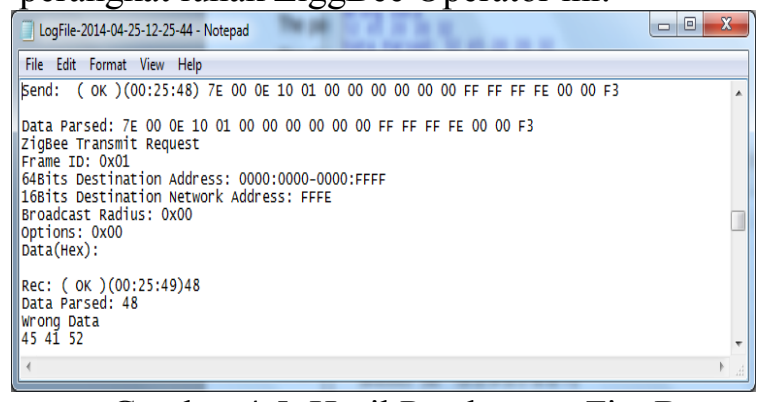

Gambar 4.5 Hasil Pembacaan ZiggBee Untuk Transmit Data

Setiap paket pengiriman data pembacaan frame Api di ziggbee operator dalam penelitian ini diawali dengan $7 \boldsymbol{E}$. Berikutnya diikuti dengan panjang data byte 00yang dikirim dalam paket terhitung setelah panjang byte. Byte berikut menyatakan jumlah register $\boldsymbol{O E}$ kemudian dilanjutkan dengan byte berikut yang menyatakan pengisian data/paket data yaitu 10 01 . Byte yang menyatakan 000000000000 $\boldsymbol{F F} \boldsymbol{F F}$ sebagai Serial Number address untuk 64bits dan $\boldsymbol{F F} \boldsymbol{F E}$ menyatakan untuk serial number network address. Selanjutnya byte 00 menyatakan jauh pengiriman data dan byte 00 terakhir menyatakan status pengiriman paket data

Berikut paket penerimaan data pembacaan frame API yang menyatakan rec dengan byte $\mathbf{4 8}$ di aplikasi ziggbee ini menyatakan paket data itu bagus atau tidak bagus. Untuk byte terakhir menyatakan pembacaan sensor dalam penelitian ini dengan byte $4541 \quad 42$ yang berbunyi kesalahan data atau yang dimaksud dengan kesalahan pembacaan data sensor.

\section{KESIMPULAN}

Berdasarkan penelitian yang telah dilakukan, dapat diambil kesimpulan sebagai berikut :

1. Pembacaan Kekuatan sinyal RSSI yang terbesar pada pengiriman data modul Xbee seri 2 didalam ruangan mampu mencapai 99 -dbm dengan penghalang yang menghalanginya tidak begitu banyak.

2. Pembacaan Kekuatan sinyal RSSI yang tercil pada pengiriman data modul Xbee seri 2 didalam ruangan mampu mencapai 71 -dbm dikarenakan saat Pembacaan sinyal ini penghalang yang menghalanginya begitu banyak. 
3. Dari pengujian yang bahwa pembacaan sinyal RSSI ini lebih kuat atau lebih besar berarti penghalang disekitar sinyal RSSInya tidak begitu banyak kalau pembacaan sinyal lebih rendah atau lebih kecil berarti menandakan penghalang yang disekitar begitu banyak yang menghalangi. Dan dalam pengujian ini juga ada yang berpengaruh yaitu jarak antara Router dan Coordinator.

\section{DAFTAR PUSTAKA}

[1].M. Hassan Jamil, Abid Ali Tahir, Ahmad Mudassir and Shakeebur Rehman IMPLEMENTASION OF REAL TIME LOCATION SYSTEM (RTLS) OF BLIND OBJECT USING ZIGBEE NETWORKWorld Applied Sciences Journal 20 (11): 1534-1537, 2012.ISSN 1818-4952

[2].Sharly Joana Halder, Joon-Goo Park,and Wooju Kim,Yonsei University, Seoul, Kyungpook National University, Daegu Republic of Korea . ADAPTIVE FILTERING FOR INDOOR LOCATION USING Zigbee RSSI AND LQI MEASUREMENT.

[3].Goran Horvat, Damir Šoštarić, Drago ŽagarPower Consumption and $R F$ Propagation Analysis on ZigBee XBeeModules for ATPC

[4].S.R. Vijayalakshmi and S. Muruganand."REALl-TIME MONITORING OF UBIQUITOUS WIRELESS ECG SENSOR NODE FOR MEDICAL CARE USING ZIGBEE'.International Journal of Electronics. Vol. 99, No. 1, January 2012, 79-89

[5]. Ummi Nurulhaiza Za'bahand O.Sidek DISTANCE VERIFICATION FOR WIRELESS ENVIRONMENT MONITORING SYSTEM USING RSSI.

[6].Thanapong Chuenurajit, DwiJoko Surosoand Panarat Cherntanomwong. IMPLEMENTATION OF RSSI-BASED 3D INDOOR LOCALIZATION USING WIRELESS SENSOR NETWORKS BASED ON ZIGBEE STANDART.

[7].Amine CHERIET, Mohamed USLIM, Kamel AIZI .University of science and Technology Oran USTOMB "LOCALIZATION IN A WIRELESS
SENSOR NETWORK BASED ON RSSI AND ADECISION TREE".

[8].S. A. Mitilineos, D. M. Kyriazanos, O. E. Segou,J. N. Goufas and S. C. A. Thomopoulos."INDOOR

LOCALIZATION WITH WIRELESS SENSOR NETWORKS". Progress In Electromagnetics Research, Vol. 109, $441\{474,2010\}$.

[9]. Theodore S.Rappaport. "WIRELESS COMMUNICATIONS - PRICIPLES AND PRACTICE.

\section{Biodata Penulis}

Fadhli Palaha lahir di Pekanbaru tahun 1983, memperoleh gelar S.T. dari Jurusan Teknik Elektro SekolahTinggi Teknologi Pekanbaru dan saat ini sedang menempuh pendidikan S2 pada Jurusan Teknik Elektro Universitas Andalas. 